\title{
RELIABILITY COMPLIANCE TESTING OF ELECTRONIC COMPONENTS FOR CONSUMER ELECTRONICS
}

\author{
E. PRZYBYL and E. PECIAKOWSKI \\ Gorlicka $11 \mathrm{~m} 30,02-130$ Warszawa, Poland
}

(Received June 29, 1981; in final form October 31, 1983)

In this paper the organisation of reliability compliance testing of electronic components in Poland is discussed. The aim of the testing is to find the reliability of the components to both producer and user and hence to establish reliability for the two parties. The system described is derived from standard methods and has two aims. These are:-

1) To enable periodical checks of production to be made.

2) To estimate the reliability level of the components produced.

Sampling plans are constructed on the basis of Weibull distributions. Individual life tests are performed to compare the reliability levels with those in the specification, and also to enable data to be accumulated for calculation of average failure rates. These tests are supervised by the quality centre UNITRA-ELECTRON. The centre is then in a position to provide reliability data on electronic components for the designers and producers of electronic equipment.

The system of reliability compliance testing given in the paper will be effective if the tests are performed frequently. The aim is also to achieve results in the shortest possible time. In order to achieve these aims accelerated life testing has been investigated.

Applicability of techniques, including that of accelerated life testing, to the study of reliability of polyester capacitors is examined.

\section{INTRODUCTION}

The present paper was originally given as a lecture in the Technical Sessions Programme of Productronica 1979, held in Munich in November of that year. As a result of the discussions held and comments received the present paper has been written.

It would appear that the reliability problems of consumer electronics are widely known. This implies that they do not concern a single firm or a particular country. General agreement on reliability has to be reached between manufacturers and users of components for consumer electronics. In the case of professional electronics involving military, space, and professional industrial uses, problems have already been tackled and normalised views on reliability have been evolved. However, in the case of consumer electronics these problems have not been entirely eliminated. This situation exists due to the economic problems which influence the limitation of activities in the sphere of general purpose components. Furthermore, there is an understandable unwillingness of the manufacturers of components and equipments to reveal the necessary data such as reliability level, reliability assurance methods used and the test organisation involved.

This paper presents methods for reliability testing which have become acceptable by the Polish industry associated with electronic component manufacture, particularly with regard to radio and TV devices. It is worth emphasising that the system to be described concerns only those components for which classical reliability tests are required. It is not intended to discuss physical compliance testing, screening tests etc. 
Previous lectures have been presented which discuss reliability testing methods in a theoretical and mathematical manner. However, few authors describe practical detail of their systems. This paper, however, which is in the nature of a review, gives practical details of reliability control by compliance testing methods.

\section{SYSTEM OF RELIABILITY COMPLIANCE TESTING USED IN UNITRA-ELEKTRON}

\section{General Information}

Although nowadays there are methods allowing us to shorten the testing time and although nondestructive accelerated tests have been introduced into the technological process (e.g. Real Time Control of RCA) the most important role in reliability assurance still belongs to the test organization. The general trend is to acquire, in a time that is as short as possible, reliable and full information on reliability levels. This is especially true for general purpose components.

The system mentioned above requires an appropriate organization of the reliability compliance testing. The basic rules of the system are defined, among others by IEC Publications $409,{ }^{1} 410,{ }^{2}$ and $605-7 .^{3}$

\section{Rules of the System}

The testing procedure covers individual families of components, (i.e. components from one technological area) or groups of components, within one family, if they differ in reliability level. The family of components implies products of similar construction and technology. These products must be produced by an individual manufacturer who applies the same standards with regard to materials and methods throughout production.

The mathematical aspect of the system is based on the assumption that electronic components destined for consumer electronics are characterized by a

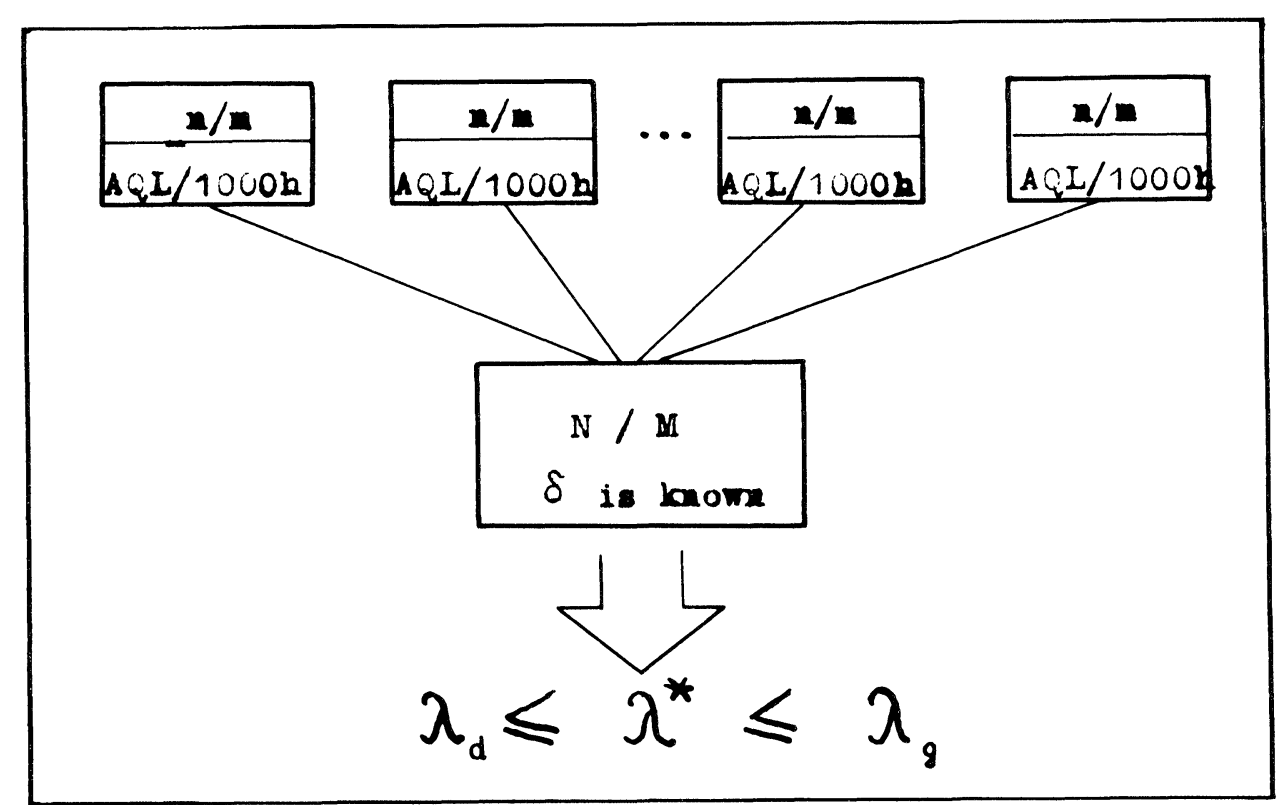

FIGURE 1 The scheme of the System of Reliability Compliance Testing of electronic components. 


\begin{tabular}{|c|c|c|c|c|c|c|}
\hline \multirow{3}{*}{$\begin{array}{l}\text { Cone. } \\
\text { Interv }\end{array}$} & \multirow{3}{*}{$\begin{array}{c}\text { Shape } \\
\text { par } \\
\delta\end{array}$} & \multicolumn{2}{|c|}{ 0ne-year teat } & \multicolumn{3}{|c|}{ "Pert1al" tests } \\
\hline & & \multirow{2}{*}{$\begin{array}{l}\text { accum } \\
\text { sample } \\
\text { size N }\end{array}$} & \multirow{2}{*}{$\begin{array}{c}a \operatorname{ccop} t \\
n \text { umb or } \\
M\end{array}$} & \multirow{2}{*}{$\begin{array}{c}Q Q L / 1000 \\
\%\end{array}$} & \multicolumn{2}{|c|}{ Samplíne plan $\mathbf{n} / \mathbf{a}$} \\
\hline & & & & & $\overline{\operatorname{variant} A}$ & $\operatorname{varlant} B$ \\
\hline $\begin{array}{l}\varphi \\
\text { in } \\
\text { in }\end{array}$ & $\begin{array}{l}1 / 3 \\
1 / 2 \\
1 \\
4 / 3 \\
2\end{array}$ & $\begin{array}{r}894 \\
1340 \\
2670 \\
3570 \\
5340\end{array}$ & $\begin{array}{l}3 \\
3 \\
3 \\
3 \\
3\end{array}$ & $\begin{array}{l}0,65 \\
0,4 \\
0,25 \\
0,15 \\
0,1\end{array}$ & $\begin{array}{r}80 / 1 \\
125 / 1 \\
200 / 1 \\
315 / 1 \\
500 / 1\end{array}$ & $\begin{array}{l}125 / 2 \\
200 / 2 \\
315 / 2 \\
500 / 2 \\
800 / 2\end{array}$ \\
\hline $\begin{array}{l}0 \\
0 \\
0 \\
0 \\
0\end{array}$ & $\begin{array}{l}1 / 3 \\
1 / 2 \\
1 \\
4 / 3 \\
2\end{array}$ & $\begin{array}{r}1793 \\
<680 \\
5356 \\
7173 \\
13000\end{array}$ & $\begin{array}{l}5 \\
5 \\
5 \\
5 \\
5\end{array}$ & $\begin{array}{l}0,4 \\
0,<5 \\
0,15 \\
0,1 \\
0,065\end{array}$ & $\begin{array}{r}200 / 2 \\
315 / 2 \\
500 / 2 \\
800 / 2 \\
1250 / 2\end{array}$ & $\begin{array}{r}315 / 3 \\
500 / 3 \\
800 / 3 \\
1250 / 3 \\
2000 / 3\end{array}$ \\
\hline
\end{tabular}

FIGURE 2 Sampling plans of reliability compliance testing and reliability requirements (example).

Weibull failure-in-time distribution. Parameters of this distribution, i.e. the shape factor $\delta$ and scale $Q$, are assumed or known from the determination tests. ${ }^{4,5}$ These tests are carried out on the initial production groups of the components as a qualifying test. The shape factor, $\delta$, is assumed from previous experience with components of a similar construction, and produced under similar conditions. If this is not possible, a first approach value of $\delta=1$ is assumed (i.e. an exponential distribution). ${ }^{3}$

Partial testing of a continuing series of lots are the basic elements of the present system with the lots being examined over a single year. The controlled reliability level is defined by the confidence interval of the assessed failure rate $\lambda$ (Figure 1). Consequently the plan of one-year testing can be defined for a given value of the parameter, $\delta$, by the indicator $\mathrm{AQL} / 1000 \mathrm{~h}$. Examples of the testing plans and of their corresponding intervals and for different fixed values of $\delta$ are shown in Figure 2. These examples cover two versions of the partial tests for a different acceptable number of failures.

1000 hours has been accepted here as the basic testing time. However, there is a possibility of shortening this time in the case where an adequate change of AQL and of the sample size can still allow the determination of the parameter $\delta$. The tests are carried out successively on products chosen by lot in established intervals, not less than eight times a year. The number of partial tests and the sample size are chosen in such a way as to give a one year testing plan. Thus it is possible to check the assumed reliability level. Part of the partial tests are carried out over a period longer than $1000 \mathrm{~h}$. This is to permit the verification of the type of failure distribution used and is undertaken every 2-3 years.

Every year the testing plans and the rules accepted by a single manufacturer are coordinated with the controlling institution. This function is fulfilled by the Quality Center UNITRA-ELEKTRON.

\section{Registration and the Usage of the Results}

Realization of the basic aim of this system of compliance testing, i.e. reliability assurance of the components, requires proper interpretation of the results and their prompt delivery to the manufacturer's component department. Thus all the results and the number of failures are registered on special forms. For easier orientation 


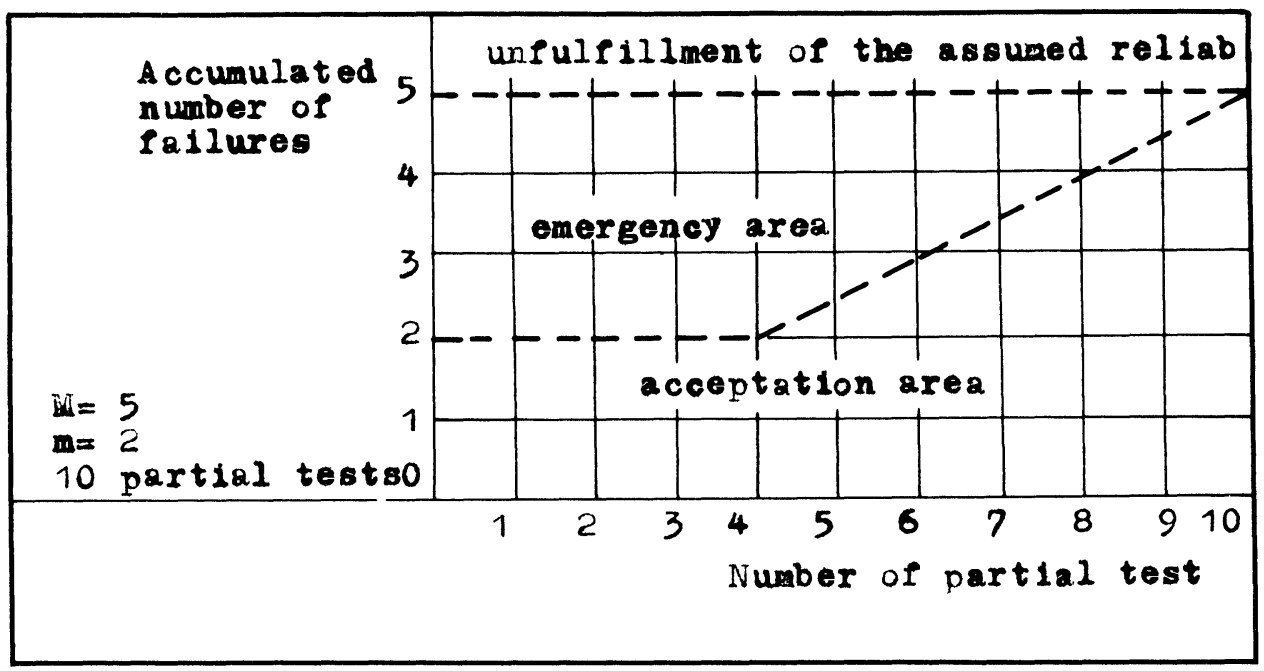

FIGURE 3 Diagram for registration of reliability compliance testing results.

on the producer's part, a diagram is constructed. This summarises the number of failures that has occurred up to the moment of the final partial test and the results are plotted on it (see Figure 3). The diagram plane has been divided into three regions. The broken line stands for the limits of the acceptance region and it gives the admissible increment in the number of failures during a year. The straight horizontal line defines the emergency region and it reflects the number of failures taken from one-year testing plan. Above this line there is the region of unfulfillment of the assumed reliability level.

Results obtained in testing are primarily destined for the manufacturer. They are also transferred to the Quality Centre UNITRA-ELEKTRON, which has all the equipment for carrying out verification tests. In the case where the reliability requirements, $A Q L / 1000 \mathrm{~h}$, are the specifications agreed with the customers of the components, then the results are also delivered to the buyers after the finish of each of the partial tests. The same happens with the results of the "periodical testing". ${ }^{8}$

Thus the system is involved with the checking of the reliability level of all the components from the batch production, and the manufacturer of the consumer electronics takes an active part in the process. Also the data transferred to the Quality Centre helps in evaluating the average value of failure rate of the components. From the accumulated data and using the Bayesian formula it is possible to define the dimension $\lambda^{*} \cdot{ }^{11,12}$ The calculated values of the failure rate applied by the manufacturer in predicting the reliability are printed in special bulletins which are then delivered to the buyers of the components.,

\section{ACCELERATED RELIABILITY TESTS IN THE SYSTEM OF CHECKING PLASTIC FILM CAPACITORS}

\section{The Basis of the Method}

A reliability compliance test system is effective when tests are carried out frequently and results obtained in as short a time as possible. Thus there is a 


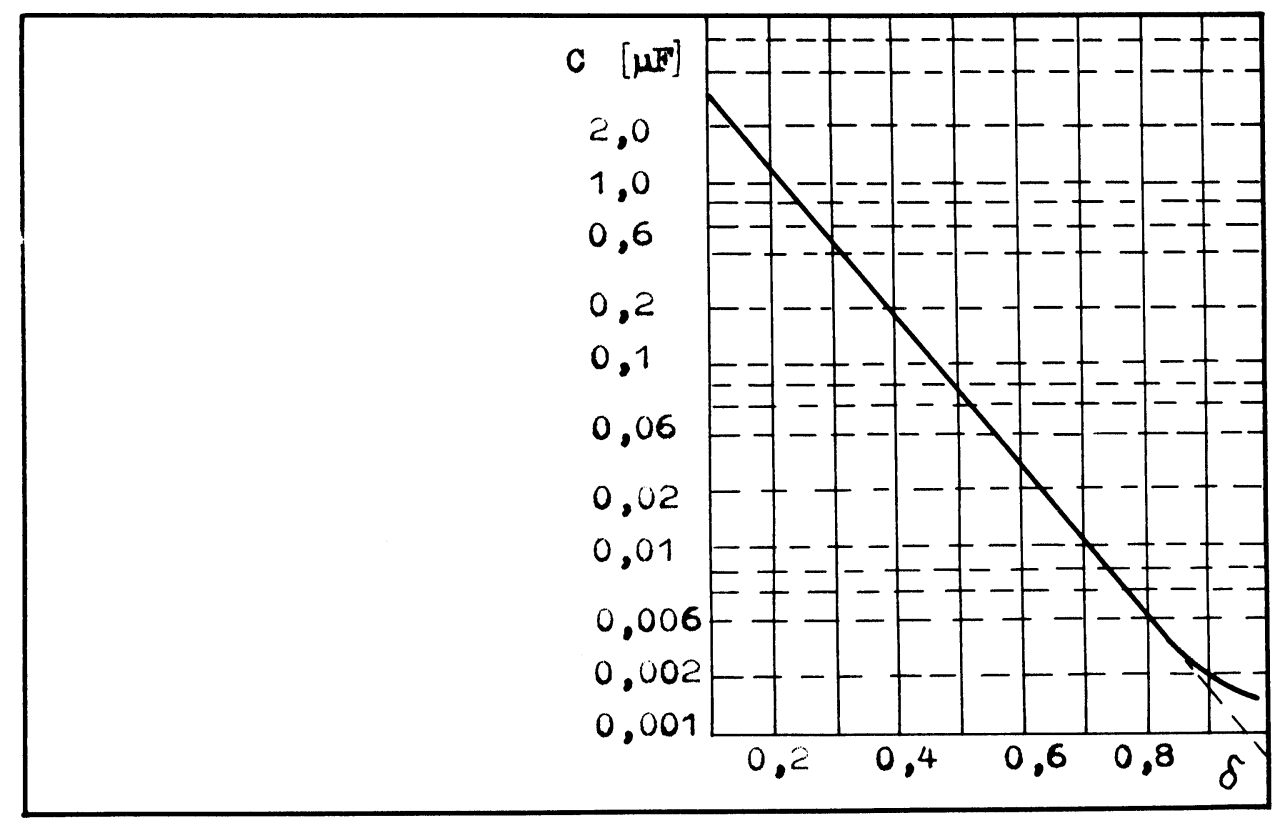

FIGURE 4 Dependence the shape parameter $\delta$ on capacity of polyester film capacitors.

preference for the accelerated methods based on extreme test conditions (test-stress levels above maximum rated conditions), ${ }^{5,6}$ These methods quickly supply us with data on the basic failure mechanisms, and due to the possibilities of converting them into the typical use stress conditions they allow us to check the assumed reliability requirements, $(\mathrm{AQL} / 1000 \mathrm{~h})$, as agreed with the receiver of the components.

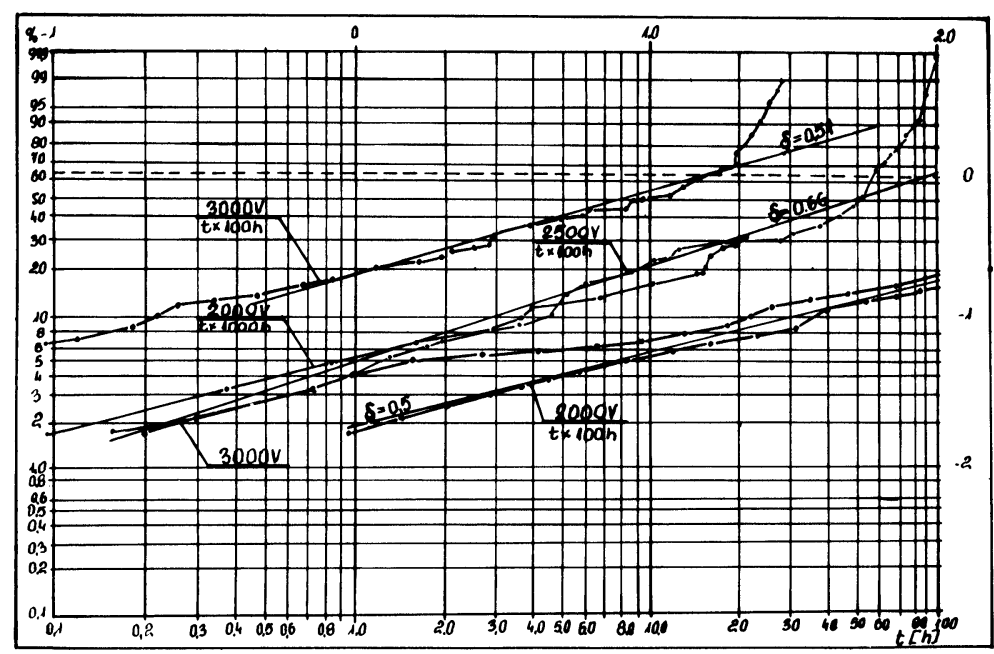

FIGURE 5 Probability of failure for polyester film/foil capacitors. (Weibull chart). $U_{N}=400 \mathrm{~V}$, $\mathrm{T}_{\mathrm{Amb}}=40^{\circ} \mathrm{C}$. 


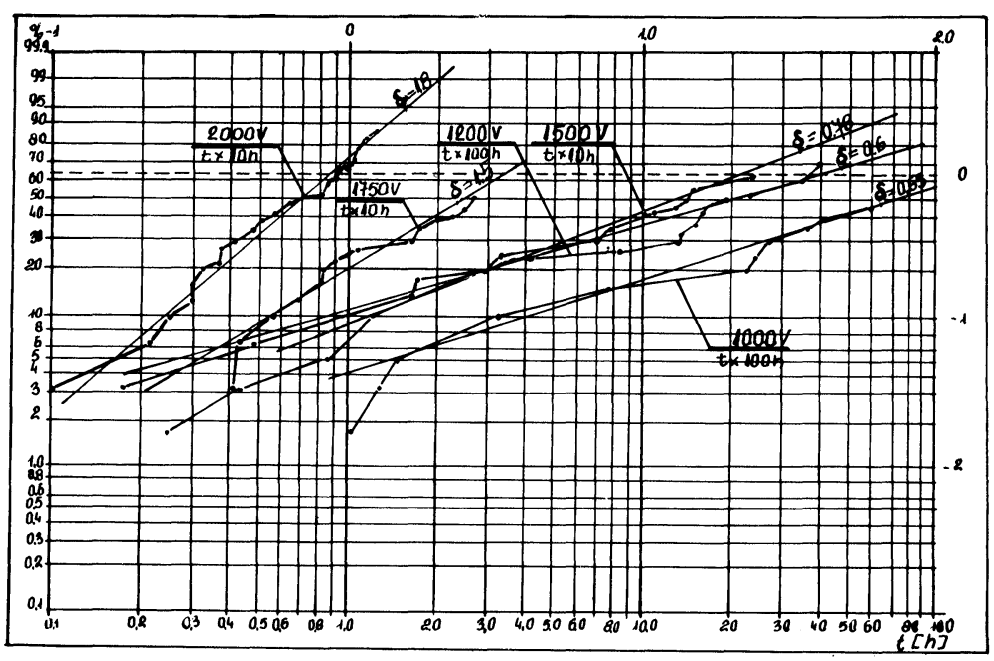
FIGURE $6 \quad$ Probability of failure for polyester film/foil capacitors. (Weibull chart). $U_{\mathrm{N}}=400 \mathrm{~V}$,
$\mathrm{T}_{\text {Amb }}=85^{\circ} \mathrm{C}$.

The methodology, perfected and applied for several years in UNITRA-ELEKTRON for plastic film capacitors (as, for example, polyester), may serve here as an example of an application of the accelerated method in the system of compliance testing.?

This methodology is based upon the following requirements obtained during tests:-

a) The parameter $\delta$ depends logarithmically on capacity (as illustrated in Figures 4 and 10). See also Mil Hdbk No. 217C.10

b) The life distribution is a Weibull distribution with shape parameter $\delta<1$ in the temperature range $+40^{\circ} \mathrm{C}+120^{\circ} \mathrm{C}$. (Figures 5,6 and 7.)

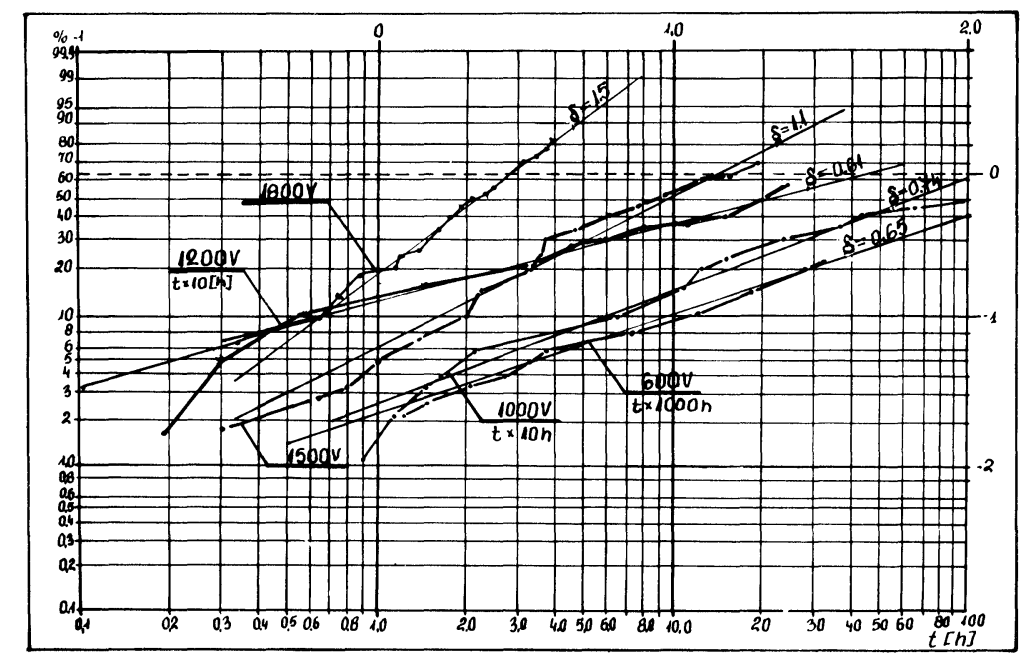

FIGURE $7 \quad$ Probability of failure for polyester film/foil capacitors. (Weibull chart). $U_{\mathrm{N}}=400 \mathrm{~V}$,
$\mathrm{T}_{\text {Amb }}=100^{\circ} \mathrm{C}$. 


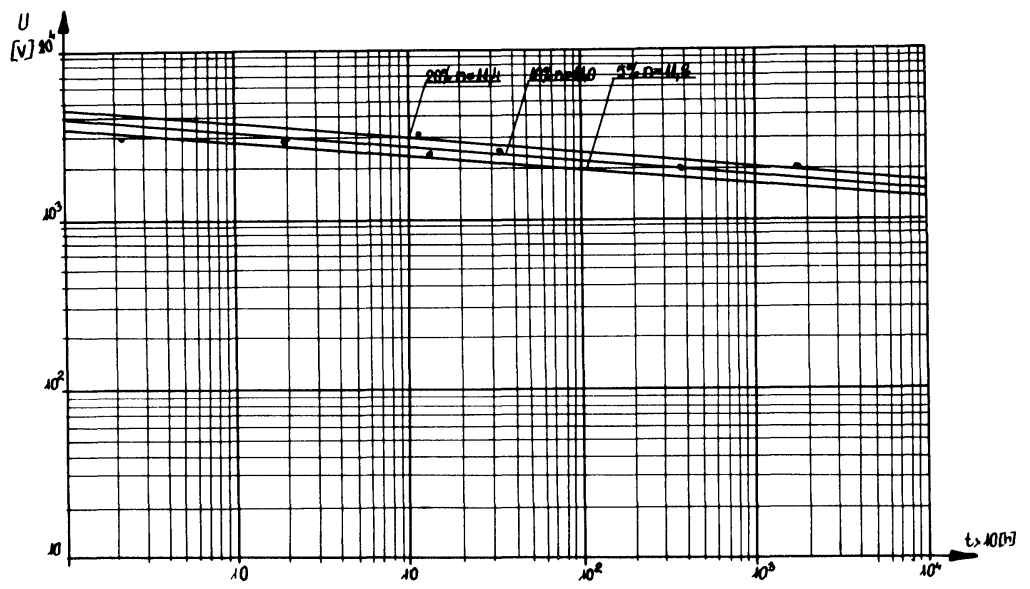

FIGURE 8 Life curves of polyester film/foil capacitors. $U_{N}=400 \mathrm{~V}, \mathrm{~T}_{\text {Amb }}=40^{\circ} \mathrm{C}$.

c) The parameter, $\delta$, does not change as a function of voltage and testing temperature in the following value range of the electric field $\mathrm{E}_{\mathrm{g}}$ :

$\mathrm{E}_{\mathrm{g}}<160 \mathrm{~V} / \mu \mathrm{m}$ in temperature $40^{\circ} \mathrm{C}$

$\mathrm{E}_{\mathrm{g}}<100 \mathrm{~V} / \mu \mathrm{m}$ in temperature $85^{\circ} \mathrm{C}$

$\mathrm{E}_{\mathrm{g}}<90 \mathrm{~V} / \mu \mathrm{m}$ in temperature $100^{\circ} \mathrm{C}$

$\mathrm{E}_{\mathrm{g}}<56 \mathrm{~V} / \mu \mathrm{m}$ in temperature $120^{\circ} \mathrm{C}$

d) The dependence of life upon the voltage on the capacitor, $\tau$, is expressed by a power function where

$\tau=\operatorname{AU}^{-\mathrm{n}}$ (see Figures 8 and 9).

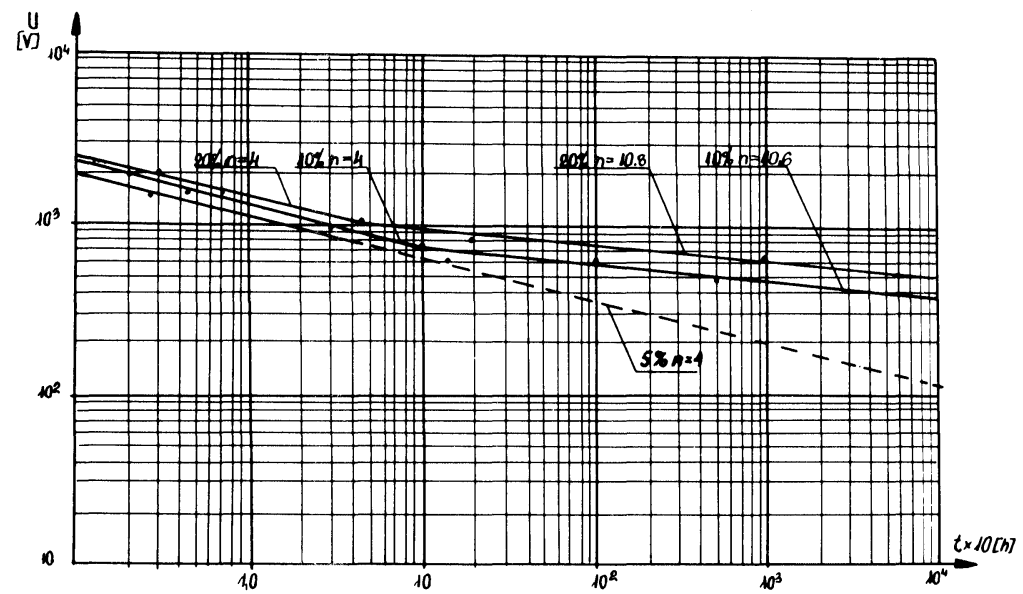

FIGURE 9 Life curves of polyester film/foil capacitors. $U_{N}=400 \mathrm{~V}, \mathrm{~T}_{\mathrm{Amb}}=85^{\circ} \mathrm{C}$. 


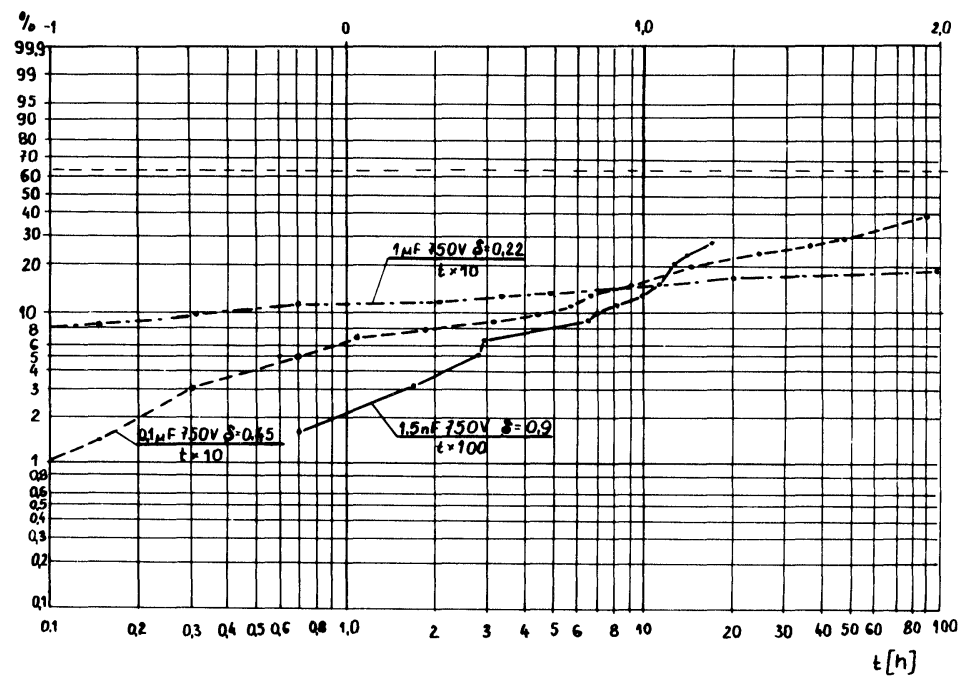

FIGURE 10 Probability of failure for polyester film-foil capacitors with different capacity: $C_{n}=1,5 \mathrm{nF}$; $\mathrm{C}_{\mathrm{n}}=0,1 \mu \mathrm{F}$ and $\mathrm{C}_{\mathrm{n}}=1,0 \mu \mathrm{F}$./Weibull distrib.chart/.

e) The exponent $\mathrm{n}, \approx 10$ and it depends neither on temperature nor on voltage when the electric field, $E_{g}$, is as indicated in paragraph (c)

f) The voltage has been chosen as the over stressing parameter since temperature in the interval of $+40^{\circ} \mathrm{C}$ to $120^{\circ} \mathrm{C}$ exerts little influence on the kinetics of the degradation process.

g) For the failure criteria we accepted that:-

(i) dielectric film breakdown

(ii) $\frac{\Delta \mathrm{C}}{\mathrm{C}} \geqslant 2 \frac{\Delta \mathrm{C}}{\mathrm{C}}$ (after endurance test)

(iii) $\operatorname{tg} \delta \geqslant 2 \operatorname{tg} \delta \quad$ (after endurance test)

(iv) $\quad \mathbf{R}_{\text {is }} \leqslant 0.01 \mathbf{R}_{\text {is }}$ (after endurance test)

When the same probability of failures is assumed there is then the following dependence between life $\tau_{\mathrm{n}}$ (under the normal working voltage, $U_{n}$ ) and life $\tau_{\mathrm{p}}$ (when the voltage is above normal, $\mathrm{U}_{\mathrm{p}}$ ):-

$$
\tau_{\mathrm{n}}=\tau_{\mathrm{p}}\left(\mathrm{U}_{\mathrm{p}} / \mathrm{U}_{\mathrm{n}}\right)^{\mathrm{n}}
$$

After simplification the failure rate in overstress conditions, $\lambda_{\mathrm{p}}$, reduces to the following formula:

$$
\lambda_{\mathrm{p}} \simeq\left\{\frac{\mathrm{m}^{*}}{\mathrm{~N} \tau_{\mathrm{p}}}\right\}
$$

where $\tau_{\mathrm{p}}$ - time of the accelerated test

$\mathrm{N}$ - sample size

$\mathrm{m}^{*}$ - number of failures in time, $\tau_{\mathrm{p}}$ 
Using equations (1) and (2) the failure rate under normal conditions has been fixed as follows:

$$
\lambda_{\mathrm{n}}=\lambda_{\mathrm{p}}\left(\mathrm{U}_{\mathrm{n}} / \mathrm{U}_{\mathrm{p}}\right)^{\mathrm{n}}
$$

Accelerated Test Methods for Polyester Capacitors

The normal range of work temperatures (i.e. $-40^{\circ} \mathrm{C}+85^{\circ} \mathrm{C}$ ), has been applied for the temperature test of the capacitors. Due to the high level of reliability, high values of the electric field have been used:-

$E_{p}=140 \mathrm{~V} / \mu \mathrm{m}$ when the temperature $=40^{\circ} \mathrm{C}$

$\mathrm{E}_{\mathrm{p}}=80 \mathrm{~V} / \mu \mathrm{m}$ when the temperature $=85^{\circ} \mathrm{C}$

These values have been chosen in such a way as to fulfill the condition where $\mathrm{m}(\mathrm{t}) / \mathrm{N}=0.1$ for the testing time $\tau_{\mathrm{p}} \geq 100 \mathrm{~h}$. Where $\mathrm{m}(\mathrm{t})$ is the number of failures in time t. For capacitors where the normal voltage $U_{n}=250 \mathrm{~V}$, the test voltage at $40^{\circ} \mathrm{C}, \mathrm{U}_{\mathrm{p}}$, is given by $\mathrm{U}_{\mathrm{p}} \simeq 5 \mathrm{U}_{\mathrm{n}}=1300 \mathrm{~V}$.

The testing time with normal stress (i.e. under typical use conditions) is the equivalent of 100 hours testing under such conditions. Thus:-

$$
\tau_{\mathrm{n}}=100\left(\frac{1300}{250}\right)^{10}=1.4 \cdot 10^{9} \text { hours }
$$

This value is longer than the expected period during which the component, owing simply to the influence of the atmospheric conditions, should be worn out. Hence both the assigned value $\tau_{\mathrm{n}}$, as well as the corresponding $\lambda_{\mathrm{n}} \approx 1.2 \times 10^{-7} \mathrm{~h}^{-1}$ are only of a theoretical character and they cannot apply to the shorter periods in which we are especially interested, of between 1000 and 10,000 hours. Because of this the appropriate calculations have been performed based on the known life distributions. When the Weibull distribution ${ }^{9}$ is assumed then the failure rate appropriate for the normal conditions for the periods we are interested in is expressed by the following formula:

$$
\lambda\left[\tau, \mathrm{U}_{\mathrm{n}}\right]=\lambda_{\mathrm{p}}\left(\frac{\mathrm{U}_{\mathrm{n}}}{\mathrm{U}_{\mathrm{p}}}\right)^{\mathrm{n} \delta} \circ\left\{\frac{\tau_{\mathrm{p}}}{\tau}\right\}^{1-\delta}
$$

where $\lambda_{p}$ is the failure rate for the testing period, $\tau_{p}$, and for a voltage $U_{p}$ above the normal.

In order to check the correctness of the applied methodology, comparative tests have been carried out in conditions where normal and above normal loads were used. Table I summarizes these tests, carried out on capacitors chosen from one production batch.

TABLE I

Test results on polyester capacitors

\begin{tabular}{ll}
\hline A & Accelerated test: $\mathrm{n}=100$ items; $\tau_{\mathrm{p}}=100 \mathrm{~h} ; \mathrm{T}=$ \\
& $85^{\circ} \mathrm{C}$ \\
& $\mathrm{U}_{\mathrm{p}}=3 \times \mathrm{U}_{\mathrm{n}}=1200 \mathrm{~V} ; \mathrm{C}=0.022 \mu \mathrm{F}$ \\
& $\lambda^{*}(5000 \mathrm{~h}, 400 \mathrm{~V})=2.6 \times 10^{-7} \mathrm{~h}^{-1}$ \\
& $\lambda^{0.9}=3.6 \times 10^{-7} \mathrm{~h}^{-1}$ \\
& Standard test: $\mathrm{n}=1000$ items; $\mathrm{t}=5000 \mathrm{~h} ; \mathrm{T}=85^{\circ} \mathrm{C} ;$ \\
& $\mathrm{U}_{\mathrm{p}}=\mathrm{U}_{\mathrm{n}}=400 \mathrm{~V}$ \\
& $\lambda^{*}(5000 \mathrm{~h}, 400 \mathrm{~V})=2 \times 10^{-7} \mathrm{~h}^{-1}$ \\
& $\lambda^{0.9}=7.8 \times 10^{-7} \mathrm{~h}^{-1}$ \\
\end{tabular}


The examples, as given above, show a good agreement of results in spite of the double extrapolation (of voltage and time) and in spite of time being a smaller sample in accelerated tests.

\section{DISCUSSION AND SUMMARY}

Three main advantages are present in the implementation of the system of reliability compliance testing of electronic components for consumer equipment developed at UNITRA-ELEKTRON. These are:-

1) the increase in reliability level of these components.

2) the regulation of mutual liability in the field of reliability among manufacturers of components and manufacturers of consumer equipment.

3) the development of information on reliability.

The results achieved in the implementation of accelerated tests on polyester capacitors described in this report is the best example to date of the improvement of reliability level. During the course of about three years a sevenfold decrease in the average failure rate has been achieved. This has been reflected in the results of the analysis of radio and TV set failures. In 1975, $0.8 \%$ of the total consumer equipment repairs were caused by failures of plastic film capacitors. Now this has been reduced down to $0.2 \%$.

\section{REFERENCES}

1. Guide for the inclusion of reliability clauses into specifications for components (or parts) for electronic equipment. IEC Publication 409. (1973).

2. Sampling plans and procedures for inspection by attributes. IEC Publication 410, (1973).

3. Equipment reliability testing. Part 7: Compliance test plans for failure rate and mean time between failures assuming constant failure rate. IEC Publication 605-7, (1978).

4. H.P. Goode, J.H.K. Kao, Sampling procedures and tables for life and reliability testing based on Weibull distribution. VIII National Symposium on Reliability and Quality Control, Page 342. Washington (1962).

5. H. Jackson, D.S. Campbell, A Manufacturers Approach to Reliability in Capacitor Production for the Domestic Market. The Radio \& Electronic Engineer, 48, pp 201-205. (1976).

6. H. Wayne, Evaluating Capacitor Reliability. Electronic World, pp 42-44. June, (1978).

7. E. Przybyl, Przyspieszone badania czasu zycia kondensatorow tworzywowych poliestrowych. Praca doktorska, Biblioteka Politechniki Wroclawskiej.

8. Reliability information sheet for components (or parts) based on laboratory test. IEC Publication 319A, (1972).

9. G.C. Stone, R.G. van Heeswijk, Parameter Estimation for the Weibull Distribution. IEE Trans. Electr. Insul. E 1-12, No. 4, Aug. (1977).

10. Mil Hdbk. 217C. Reliability Prediction of Electronic Equipment. pp 253-261. April (1979).

11. J. Temler, Ocena Niezowodnosci przy zastosowaniu metody Bayesa. Proceedings 1980 National Conference on I:lectronic Equipment Reliability Rosciszow, Poland. pp 47-58. (1980).

12. Special Issue on Bayesian Reliability Techniques. Transactions on Reliability. 2-21. No. 3. August (1972). 

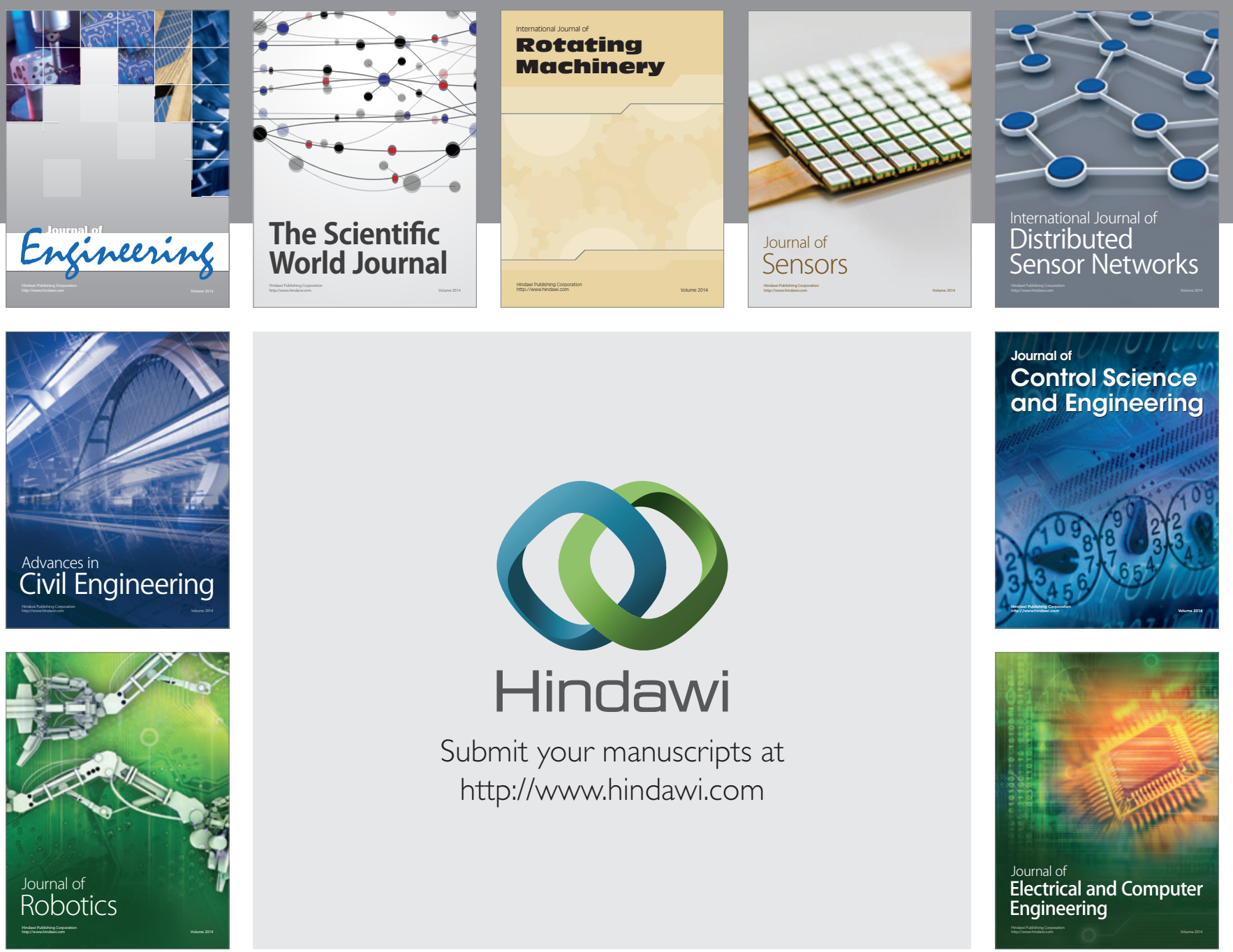

Submit your manuscripts at

http://www.hindawi.com
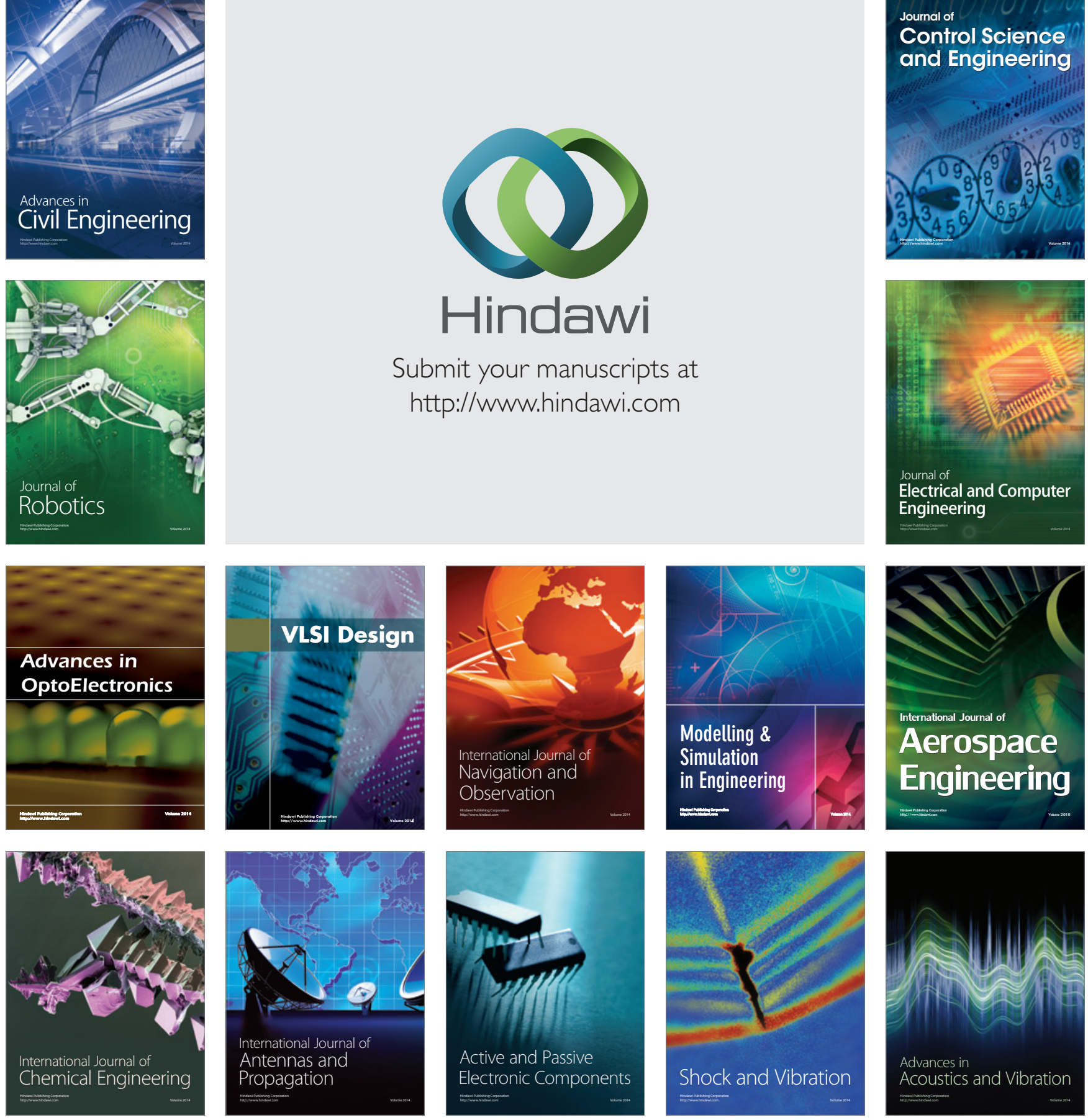